Hydrology and Earth System Sciences, 9(4), 431-448 (2005) C EGU

\title{
An empirical method for estimating future flood risks for flood warnings
}

\author{
K. Hlavcova, S. Kohnova, R. Kubes, J. Szolgay and M. Zvolensky \\ Department of Land and Water Resources Management, Faculty of Civil Engineering, Slovak University of Technology, Radlinskeho 11,81368 Bratislava, Slovakia
}

Email for corresponding author: hlavcova@svf.stuba.sk

\begin{abstract}
Since medium and long-term precipitation forecasts are still not reliable enough, rough estimates of the degree of the extremity of forthcoming flood events that might occur in the course of dangerous meteorological situations approaching a basin could be useful to decision-makers as additional information for flood warnings. One approach to answering such a problem is to use real-time data on the soil moisture conditions in a catchment in conjunction with estimates of the extremity of the future rainfall and experience with the basin's behaviour during historical floods. A scenario-based method is proposed for such a future flood risk estimation, based on an a priori evaluation of the extremity of hypothetical floods generated by combinations of synthetic extreme precipitation and previously observed antecedent pre-flood basin saturations. The Hron river basin, located in central Slovakia, was chosen as the pilot basin in the case study. A time series of the basin's average daily precipitation was derived using spatial interpolation techniques. A lumped HBV-type daily conceptual rainfall-runoff model was adopted for modelling runoff. Analysis of the relationship of the modelled historical pre-flood soil moisture and flood causing-precipitation revealed the independence of both quantities for rainfall durations lasting 1 to 5 days. The basin's average annual maximum 1 to 5 day precipitation depths were analysed statistically and synthetic extreme precipitation scenarios associated with rainfall depths with return periods of 5,20,50 and 100 years, durations of 1 to 5 days and temporal distribution of extreme rainfall observed in the past were set up for runoff simulation. Using event-based flood simulations, synthetic flood waves were generated for random combinations of the rainfall scenarios and historical pre-flood soil moisture conditions. The effect of any antecedent basin saturation on the extremity of floods was quantified empirically and critical values of the basin saturation leading to floods with a higher return period than the return period of precipitation were identified. A method for implementing such critical values into flood risk warnings in a hydrological forecasting and warning system in the basin was suggested.
\end{abstract}

Keywords: rainfall-runoff model, annual maximum 1 to 5 day precipitation depths, antecedent basin saturation, extreme flooding, event based runoff generation, flood warning

\section{Introduction}

Extreme flood events can have severe consequences for human society. Several major flood events in Eastern Europe and worldwide over the past decade have led to concerns about the reliability of existing flood forecasting and warning systems. There is a pressing need not only to re-evaluate existing forecasting practices and quantify the uncertainty of forecasts and increase their accuracy and lead times, but also to introduce reliable pre-flood warnings. When an extreme meteorological situation that can lead to a flood causing major disruption, damage and possibly loss of life is approaching a basin, how dangerous might the resultant flood be? Since medium and long-term precipitation forecasts are still not reliable enough, warnings-based planning for flood-related emergencies could profit from an estimate of the return period of the expected flood. Such quantitative warnings may help decision-makers to become more conscious of floods and take preliminary precautionary measures well in advance. A case study-based development of such a method is presented here. The relevant methodology on extreme precipitation analysis and eventbased flood simulation is reviewed, followed by an outline of the basic methodology. The pilot basin and the spatial interpolation method used for constructing a series of daily 
precipitation depth maps is then described, followed by a short seasonality analysis of extreme precipitation over the basin and its statistical analysis. The results obtained are used as a basis for building rainfall scenarios. The lumped conceptual rainfall-runoff model used in the study for eventbased flood generation is then calibrated, followed by an analysis of the relationship between the values of the modelled historical pre-flood soil moisture and the floodcausing precipitation depths. The independence of both quantities for all the rainfall durations used serves as the basis of a simple event-based flood generator. Synthetic extreme precipitation scenarios associated with the basin's average 1 to 5 day precipitation depths with return periods of 5,20,50 and 100 years disaggregated according to the temporal distribution of the extreme rainfall observed in the past are set up for runoff simulations. Using combinations of synthetic extreme precipitation scenarios and randomly selected historical pre-flood basin saturations, a set of synthetic flood events is simulated.The effect of antecedent basin saturation on the extremity of floods is then quantified and the critical values of the soil moisture leading to floods with a higher return period than the return period of the precipitation is sought. A method for implementing such critical values into on-line flood risk warnings in the hydrological forecasting and warning system in the basin is also suggested.

\section{Review of relevant precipitation analyses and flood modelling}

The methodology proposed in this paper is mainly based on design precipitation analysis and event-based flood modelling. The estimation of design maximum precipitation depths of various durations was based mainly on the application of statistical methods. Recently, many new types of distribution functions and methods of parameter estimation have been developed in engineering hydrology. Also, methods of regional frequency analysis have become popular for estimating design values in engineering practice. For example, in Switzerland the extreme precipitation was regionalised by Geiger et al. (1986), resulting in maps of maximum 1 to 5 day precipitation depths with return periods of 2, 33, and 100 years. Jensen (1986) analysed probability distribution functions for maximum daily precipitation depths and derived maps of the distribution of their quantiles using geostatistical methods. The regionalisation of daily precipitation depths was also performed for the State of Washington, USA (Schafer, 1990). Grebner (1995) presented a statistical analysis of rainfall depths of a duration of 3 to 72 hours for the northern part of the Alps. In Germany, the research project KOSTRA analysed the annual frequencies of rainfalls lasting 5 minutes to extreme rainfalls lasting 72 hours for the observation period of 1951-1980 (Malitz, 1999; Bartels et al., 1997). Geostatistical methods have been used for the regionalisation of maximum rainfall depths with different return periods. In 1999, the UK Flood Estimation Handbook (FEH, 1999) was published; it presented a methodology for estimating the relationship between rainfall intensity, duration and annual frequency for durations lasting 1 hour to 8 days. For estimating return periods, the so-called Focused Rainfall Growth Extension (FORGEX) method was developed (Reed et al., 1999; Faulkner et al., 1999). In New Zealand, the High Intensity Rainfall Design System (HIRDS; Thompson, 2002) consists of software for estimating the design values of maximum precipitation depths as well as a rainfall mapping index. In South Africa, regional approach based on L-moments was also used for estimating precipitation depths of shorter durations ( $\leq 24$ hours) (Smithers et al., 2001).

In practice, attention has been paid to analysis of precipitation with a duration longer than 24 hours and the spatial distribution of precipitation is increasingly being analysed. There is a wide acceptance of various new interpolation, geostatistical and statistical methods. No real preference for one methodology can be found, although methods based on L-moments and the use of the GEV probability distribution function have gained increased popularity in recent years. Since the choice of the method of design precipitation estimation is not critical for the methodology presented here, methods used in the studies originating in Germany, Austria and Switzerland will be used in this paper to derive the basin's average daily precipitation and the basin's average annual maximum 1 to 5 day precipitation depths with different return periods.

Developments in design flood estimation methods for flood protection purposes have advanced very rapidly in recent decades. The trends have been based mainly on the use of new statistical approaches (concerning both distribution functions and parameter estimation methods), the application of new principles of regionalisation, and regional flood frequency analysis (e.g. objective methods of selecting regional types such as cluster analysis, L moments-based methods). These methods will not be discussed here. Other efforts have focused on simulation techniques using rainfall-runoff models and the derived flood frequency approach (which is still far from having practical engineering relevance). Standardised procedures do not exist in these fields; both the continuous simulation and event-based approaches have been used for flood frequency estimation in a number of studies. Calver and Lamb (1996) used two models: the Probability Distributed Model and the Time-Area Topographic Model for estimating 
flood frequency for design purposes in 50 catchments in the UK. The design floods were computed using modelled POT series of floods and the Pareto distribution. Cameron et al. $(1999,2000 \mathrm{a}, \mathrm{b})$ applied the TOPMODEL within the GLUE framework using a 21-year period of rainfall and discharge observations and a stochastic rainfall generator for a 1000-year continuous simulation of floods. The rainfall model used was conditioned on observed rainfall frequency statistics. Rahman et al. (2002) presented an approach which made an explicit allowance for the probability-distributed nature of key flood-producing principles. There are also scenario-based approaches like the Swedish and Norwegian methods of spillway design based on the HBV rainfall-runoff model (Lindström et al., 1997; Bergström et al., 1992) for estimating design flood waves from standardised scenarios of extreme hydrological events in Sweden and Norway. Design floods are obtained by simulation from observed extreme hydrological factors combined into a worst-case scenario. The use of hydrological models for flood simulation is also increasing rather quickly in the pilot region of this study, especially in the retrospective analysis of the generation of extreme events, e.g. Miklánek et al. (2000) and Svoboda et al. (2000).

Hashemi, Franchini and O'Connell (2000) and Franchini, Hashemi and O'Connell (2000) used a Monte Carlo-based approach to assess the effect of climate and basin factors on the flood frequency curve and to indicate changes to which the flood frequency curve might be sensitive. The results of the first study suggested that the overall behaviour of the flood frequency curve is controlled by the probability distribution of the soil moisture at the time of the storm's arrival. The second study showed that other factors, such as the probability distribution of the soil's moisture capacity and the rainfall regime expressed through annual maximum rainfalls of over various durations, also have to be considered.

Franchini, Helmlinger, Foufoula-Georgiou and Todini (1996) extended the stochastic storm transposition technique (Foufoula-Georgiou, 1989; Wilson and Foufoula-Georgiou, 1990) to the estimation of design floods. The catchment's average cumulative rainfall depths were converted to possible peak flow values using the ARNO rainfall-runoff model for a range of fixed antecedent soil moisture conditions. The effect of these on the magnitude and frequency of a flood as compared with their respective values for a rainfall were highlighted. With respect to the aims of this paper, they stressed the importance of the role of the water storage capacity of the soil and its initial water content as the most important aspects which affect the peak runoff production process. Based on the results of a comparative analysis of a conceptual rainfall-runoff model from
Franchini and Pacciani (1991), they also recommended avoiding extremely complicated models in such studies. Franchini and Pacciani also showed that significantly different models produce basically equivalent results, so that the problem of the choice of a model may not be critical in this type of research.

Although the main principles used in the cited and similar flood modelling studies could be applied to this study, their detailed reproduction was not considered feasible. The continuous modelling approach relies on rather complicated stochastic rainfall and temperature modelling, especially when floods are caused by various atmospheric circulation patterns; the genesis and duration of flood-inducing rainfalls may vary and rainfall and floods of snowmelt origin play a role in the flood regime of a particular region (as is often the case under central European conditions). The eventbased approach may be regarded as simpler and more appropriate; however, further simplifications will be considered to reduce the difficulties inherent in determining the joint distribution of initial basin states and the magnitude and temporal distribution of extreme rainfall events. This avoids the necessity of the joint stochastic modelling of temperatures and rainfalls, when considering both rainfall and snowmelt-induced floods.

\section{Methodology}

Medium and long-term precipitation forecasts still do not offer the accuracy required for reliable medium and longterm flood forecasting. The use of ensemble forecasting is one of the ways to address this shortcoming in practice. Here, an additional possibility is suggested to aid decisionmaking in pre-flood situations. It is proposed to estimate the return period of anticipated floods based on real-time estimates of the soil moisture conditions in a catchment, in conjunction with forecast-based estimates of extreme future rainfalls. The method could serve decision-makers as preliminary information and also help increase flood awareness in the non-specialist community.

The intended use of continuously available information on the soil moisture state of a catchment invokes the need to run a rainfall-runoff model or to use other more complex methods to monitor the moisture state of the catchment in real time. Since the latter is unfeasible in practice, a simple continuously-operated conceptual rainfall-runoff model is a pragmatic choice, especially when data are sparse. Such models are run routinely by forecasting agencies and the information on the moisture status of the catchment being studied can, in principle, be made publicly available. The use of such a lumped model also avoids the need for spatially distributed information on rainfall which is routinely 
unavailable or may be highly uncertain.

The proposed method is scenario-based. It was also intended to use simple operational means and modest input requirements to design a scheme implementable in datasparse and low-tech environments. It generalises results from an analysis of the return periods of hypothetical floods simulated in a basin during past flood situations, for the real flood-causing precipitation was substituted by a synthetic event with the same duration and temporal distribution but with rainfall amounts of a given probability of exceedance.

Several simplifications have been adopted. A daily time step is considered. Since in practice it is intended to utilise real- time estimates of a catchment's soil moisture conditions as the basis for estimating the return period of coming events, only rainfall-induced floods will be considered, in order to avoid complications caused by the need to monitor the snow cover and/or simulate snowmelt or mixed floods. Strict derivation of the method would require a joint stochastic generation of pre-flood soil moisture values and synthetic rainfall inputs of various durations and temporal distributions for a flood event-based runoff simulation for flood frequency estimation. Such a joint generator would have to be built on the basis of a stochastic analysis of the structure and mutual relationships of these variables. The approach proposed here avoids such an analysis by using observed (empirical) frequencies of selected historical preflood soil moisture states and observed temporal distributions of rainfall instead of building stochastic models.

The following concrete steps are proposed. A time series of the basin's average daily precipitation depths will be derived from point rainfall measurements using spatial interpolation. A lumped daily conceptual rainfall-runoff model will be calibrated to model runoff. The climatic mechanism of the flood generation will be analysed and the origin and duration of the rainfalls which are the main causes of the floods will be identified. This analysis will be conducted for floods with crests larger than the in-bank flow (usually, a 1-year flood under Slovak conditions), since smaller floods do not represent practical dangers and are therefore not subject to warnings. The basin's average annual maximum precipitation depths of the critical durations will be analysed statistically and the design values estimated for a selected set of return periods.

The following analysis of the relationship of the pre-flood catchment soil moisture values as abstracted from the rainfall-runoff model for the selected historical floods and the flood-causing precipitation depths should support a hypothesis of the independence of both quantities for all rainfall durations to allow the use of a simple flood generation scheme.
A basin's average synthetic extreme rainfall scenarios associated with rainfall depths with given return periods will be constructed using the observed duration and temporal distributions of rainfall which caused the past floods selected. Subsequently, synthetic flood waves will be generated on an event basis using the principles of the method of fragments for random combinations of rainfall scenarios and observed historical pre-flood rainfall-runoff model states (including the catchment's soil moisture state). In the method of fragments, widely used for stochastic modelling of flows in the past (Svanidze, 1997; Srikanthan and McMahon 1980,1982), the scaled observed temporal distribution of the variable of interest, called a fragment, is considered as a model for disaggregating the stochastically generated scaling variable to a finer time (or space) resolution. The set of pre-flood model states extracted from the simulated flow series and the set of the duration and temporal distribution of flood- causing rainfall for all the simulated historical flood waves inundating the riverine areas, are considered as fragments of the initial conditions of the model and the temporal distribution of the generated rainfall depths for the event-based synthetic flood generation.

The flood generation is based on the hypothesis that the modelled basin state described by the soil moisture during pre-flood conditions in the lumped rainfall-runoff model and the magnitude of the flood-inducing rainfall are statistically independent. Thus, it is possible to combine the values from these two sets randomly to generate synthetic floods. To be consistent with the empirical data, the frequency distributions of both variables are substituted for their respective empirical distributions. This simplification would be too restrictive for event-based flood frequency analysis; however, it is seen as acceptable here, where only the variability of possible basin behaviour is explored during past events. For this reason the duration of any synthetic rainfall will also be kept equal to the duration of that causing the historical flood event; only its intensity will be allowed to change.

Subsequently, the effect of antecedent basin saturation on the extremity of floods will be analysed and quantified. The critical values of the basin saturation leading to floods with a higher return period than that of the precipitation will be sought and a method devised to implement such critical values into flood risk warnings in the hydrological forecasting and warning system in the basin.

The number of combinations generated by this approach is clearly restricted when compared with that which would be achieved by stochastic modelling of the soil moisture and rainfall. However, the purpose of this study is not to explore the effect of climatic and basin factors on the flood 
frequency curve nor is it to derive flood frequency distributions by simulation for engineering design. The aim is to use empirical information from past events in developing a simple method for the close to real-time assessment of the extremity of forthcoming floods, as expressed through their return periods and conditioned on information about the duration and extremity of the expected near-future rainfall and the pre-flood state of the basin, as expressed through a lumped catchment soil moisture value.

\section{Description of the pilot basin and input data}

In this study the Hron River basin, area $1766 \mathrm{~km}^{2}$, was selected as the pilot basin. The flood-generating mechanism in the Hron basin is complex and is characteristic of the mountainous regions of Slovakia. In such high mountainous regions, flash floods represent a threat to local villages located in narrow valleys. Due to the character of the runoff, concentration floods from rainfalls of a cyclonic origin represent the main danger to major towns and cities, including the outlet at Banska Bystrica, which was considered a target point in this study.

The Hron River basin is located in central Slovakia (Fig. 1); the minimum elevation of the basin is $340 \mathrm{~m}$ a.s.l., the maximum elevation is $2004 \mathrm{~m}$ a.s.l. and the mean elevation is $850 \mathrm{~m}$ a.s.l. Seventy percent of the basin's area is covered by forest, $10 \%$ by grasslands, $17 \%$ by agricultural land and $3 \%$ by urban areas (the digital elevation model of the basin and land-use map are shown in Figs. 2 and 3).

The time of concentration to the basin outlet in Banska Bystrica is around one day. The largest travel time of 28 hours was estimated by hydraulic routing, considering the overland and subsurface flow from the basin's cells on the catchment's boundary to the basin with the physically-based distributed rainfall-runoff model of WetSpa (Liu et al.,
2003) (taking into account the flow length, the slope, the soil properties and surface roughness as a function of the land-use). This estimate is supported by travel times (of 19 and 23 hours respectively), computed from the commonly used Kirpich and Nash formulae. Therefore, a daily time step can be considered appropriate for rainfall-runoff modelling in the basin.

The following input data from 1961-2000 were collected:

- the daily precipitation from 23 rain-gauge stations (see Fig. 2 for their location and altitudinal distribution),

- the mean daily air temperature and additional climate data from 6 meteorological stations for monthly potential evapotranspiration computations,

- and the mean daily discharges at the basin outlet in Banska Bystrica.

Given the mountainous character of the basin, with its observed orographic effects in the north-south direction, it was decided to employ spatial interpolation for estimating the basin's average precipitation, even for lumped rainfallrunoff modelling. A variety of methods, both deterministic and stochastic, can be applied to take point data from gauges and estimate total precipitation over an area. Since the precipitation does not exhibit a strong and regular altitudinal zonality at the daily level in the basin in the case of rainfall, an inverse distance interpolation was selected here for constructing an interpolated rainfall surface over the basin.

The general form of the equation for interpolation in the $\mathrm{z}(\mathrm{x}, \mathrm{y})$ plane at point $\mathrm{z}_{\mathrm{i}}$ (Meijerink et al., 1994) is:

$$
z_{0}=\sum_{i=1}^{n} w_{i} z_{i}
$$

where:

$z_{0}$ is the estimated value of the process at any point $x_{0}$ and $y_{0}$,

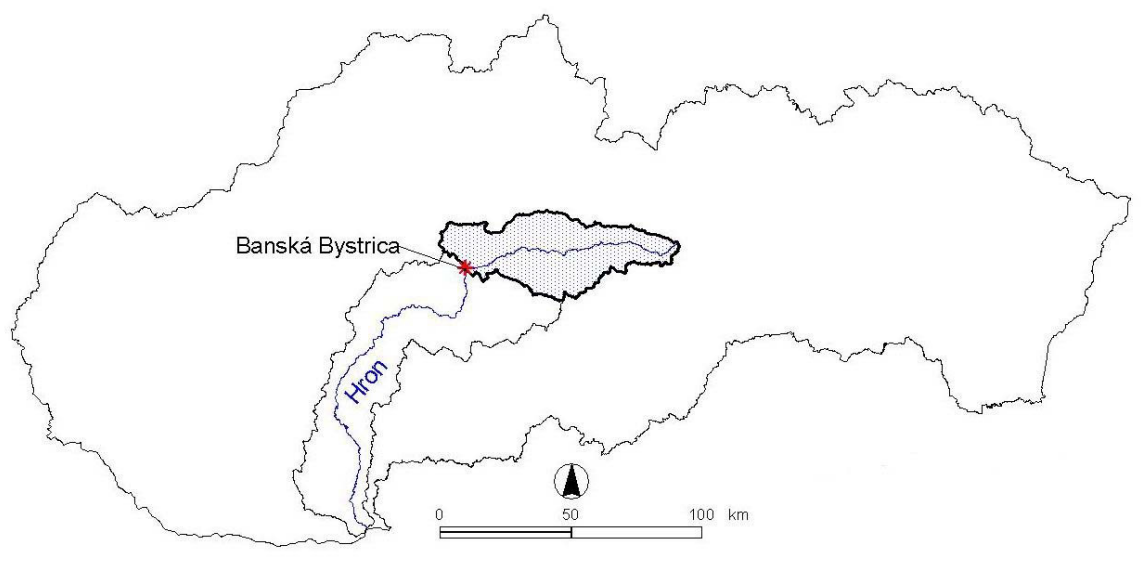

Fig. 1. Location of the Hron River basin in Slovakia 


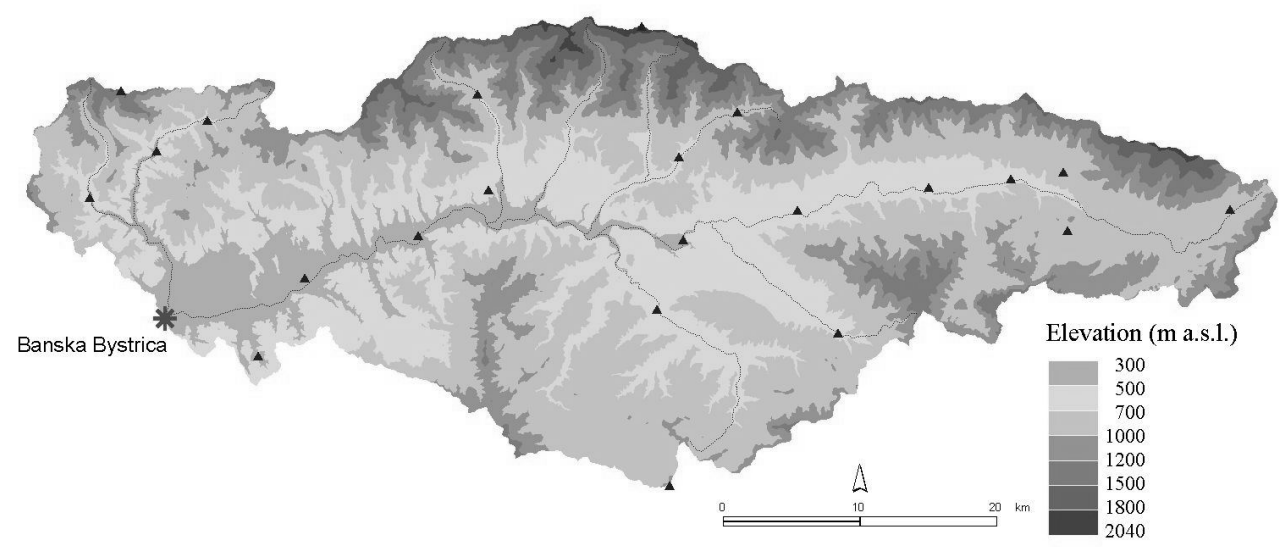

Fig. 2. Digital elevation model of the Hron River basin with rain-gauge station locations.

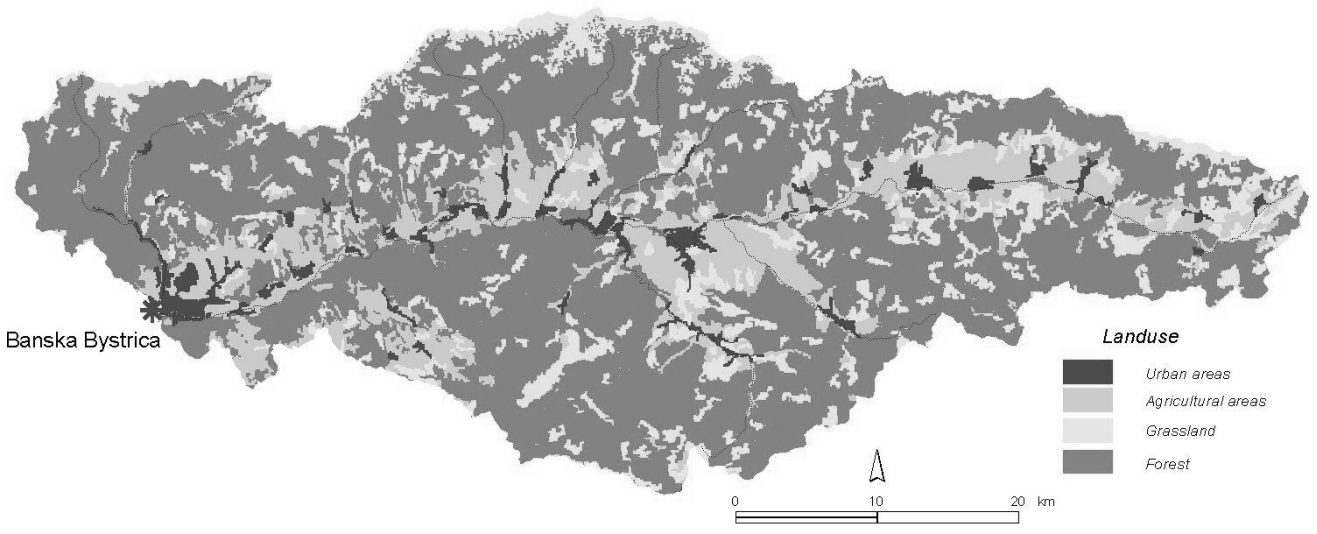

Fig. 3. Land-use map of the Hron river basin.

$w_{i}$ is the weight of the sampling point $i$, with the coordinates

$$
x_{i}, z_{i}
$$

$z_{i}\left(x_{i} y_{i}\right)$ is the observed value of the attribute at point $x_{i} y_{i}$, $n$ is the number of sampling points considered.

Using the inverse distance method, a neighbourhood around the interpolated point $x_{0}, y_{0}$ is identified, and a weighted average is taken of the observation values $x_{i}, y_{i}$ within this neighbourhood. The weights $w_{i}$ are a decreasing function of the distance between the interpolated point $x_{0}$, $y_{0}$ and the points with rainfall measurements $x_{i}, y_{i}$ :

$$
w_{i}=\frac{f\left(d_{0 i}\right)}{\sum_{i=1}^{n} f\left(d_{0 i}\right)},
$$

where $d_{0 i}$ is the distance between $\left(x_{0}, y_{0}\right)$ and $\left(x_{i}, y_{i}\right)$. The function $f\left(d_{0 i}\right)$, defined as

$$
f\left(d_{o i}\right)=\frac{1}{d_{o i}^{\beta}}
$$

with $\beta$ as a parameter, was set to be equal to 2 .

According to this procedure, precipitation maps were constructed for each day of the whole period of observations from 1961-2000. Average daily rainfall depths over the basin were computed from these grid maps.

The flood season in the region is concentrated in the warm climatic period (April to October), which is illustrated here by a routine seasonality analysis of the annual maximum floods through the seasonality index as suggested by Burn and a simple seasonality analysis of the annual maximum 1 to 5 day precipitation depths.

The Burn index is a vector that represents the variability of the date of occurrence of the selected flood events. In this case its direction is the mean date of the occurrence of the annual maximum flood peak, and the length is the variability of the date of occurrence around the mean value (for details, see Burn, 1990).

The seasonality index of Burn for the annual maximum floods in all the gauged sub-basins in the Hron basin is shown in Fig. 4 as arrows plotted at the gauging station locations. A set of gauging stations from the adjacent regions was also included to support the results. For the whole region, irrespective of the basin's size, the annual maximum floods occur mostly in the warm season of the year. This feature develops with the growing size of the sub-basins 


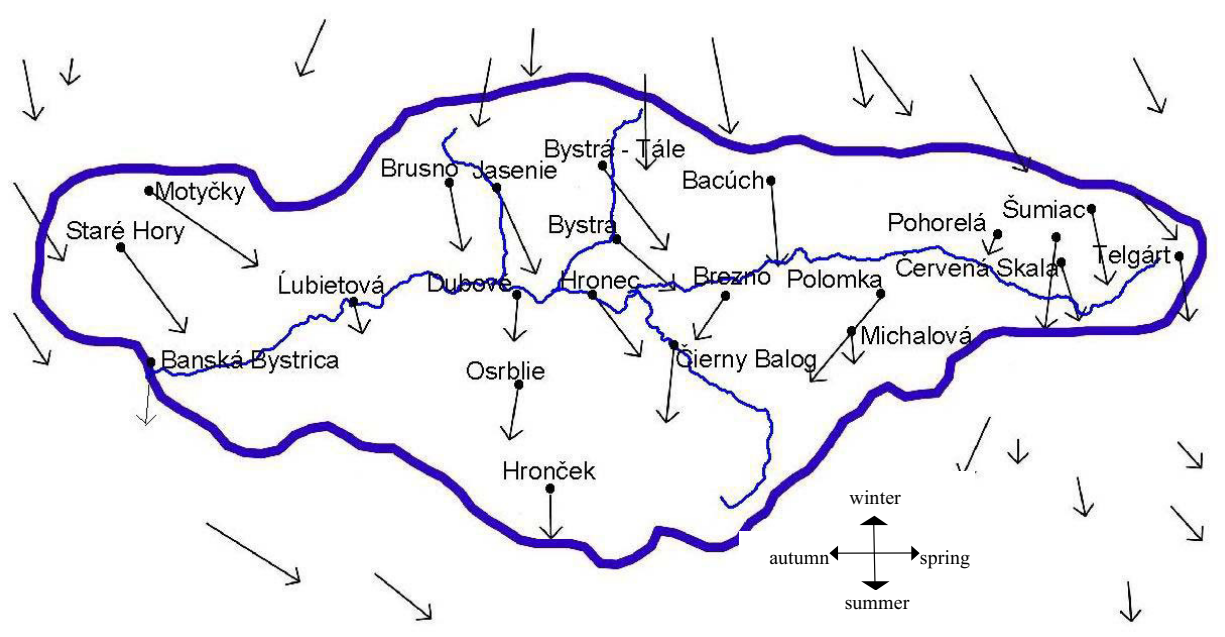

Fig. 4. Seasonality index of Burn (1990) of the annual maximum floods in all the main gauging stations of the Hron River basin and selected gauging stations in adjacent basins. The arrows indicate the directions of the main seasons.

and is also valid for the basin as a whole for the Banska Bystrica section.

Annual maximum 1, 2, 3, 4 and 5-day precipitation depths were also selected for a simple seasonality analysis from the series of basin average daily rainfall depths. Only events with continuous precipitation during the indicated number of days were considered. The frequency of occurrence of the selected events is presented in Fig. 5, which shows that the occurrence of annual maximum 1 to 5 day precipitation depths was most frequent during the warm season of the year (1.4.-30.10); the annual maximum 1-day precipitation depths occurred most frequently in July, August and October, the annual maximum 2 and 3-day precipitation depths in July and October, the annual maximum 4-day precipitation depths in June, August and October, and the annual maximum 5-day precipitation depths mainly in May, June and October. Since the occurrence of events in the winter season was negligible, the annual maximum precipitation series is mostly composed of rainfall events (the form of precipitation of winter events was not analysed further here, so rainfall may also be included there).

These findings justify the a priori selected simplification that the proposed method will be limited to rainfall-induced floods. Rainfall-induced floods represent the practical threat of flooding in the basin; thus snowmelt and rain during snow events were excluded from the analysis.

The analysis of the duration of the basin's average rainfall events causing floods larger than the in-bank flow (approximately, a 1-year flood in the Hron basin) showed that events with a duration of 1 to 5 days are significant for the occurrence of these floods from rainfall and also have to be considered as a causative effect in the modelling of the flood regime. Table 1 shows the frequency of rainfall- induced floods larger than the in-bank capacity due to rainfall events with a duration from 1 to 5 days during the period of 1961-2000. Although floods with one-day precipitation events were not frequent, given the time of the concentration, they were not excluded from the analysis.

As expected, daily temperature data exhibits welldeveloped altitudinal zonality; therefore, the basin's average daily temperature was computed as a weighted average of the station values, the weights derived as the respective areas of the altitudinal zones assigned to the stations. The same approach was used for the estimation of the basin's average monthly potential evapotranspiration, using the BudykoTomlain energy balance method.

The final basic dataset used for the development of the method was as follows:

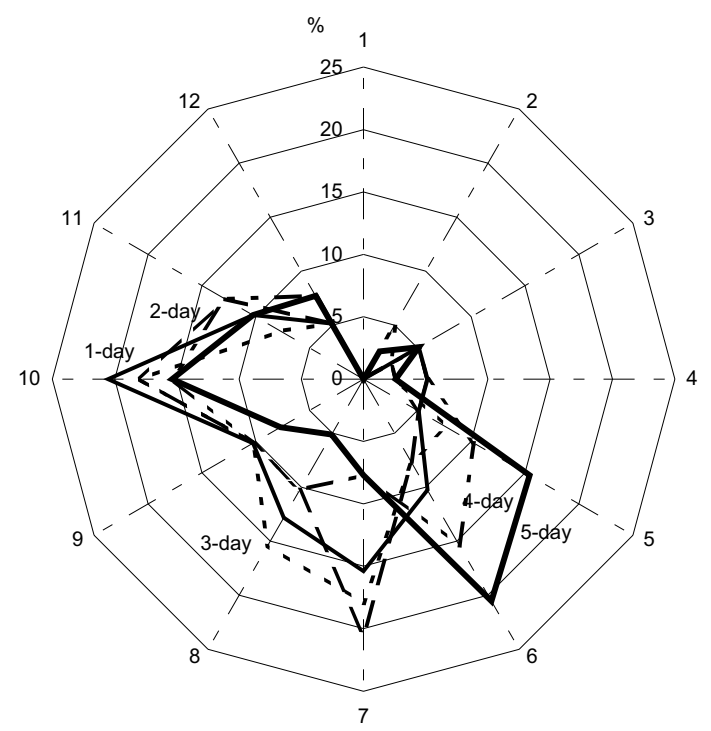

Fig. 5. Percentage of occurrence of annual maximum 1 to 5 day precipitation depths in individual months from 1961-2000. 
Table 1. Frequency of rainfall-induced floods larger than the in-bank capacity (approximately, a 1-year flood) due to rainfall events with a duration from 1 to 5 days in the 1961-2000 period in the Hron basin.

\begin{tabular}{|c|c|c|c|c|c|}
\hline Duration of rainfall (days) & 1 & 2 & 3 & 4 & 5 \\
\hline $\begin{array}{l}\text { Frequency of flood events exceeding the in-bank capacity of the Hron river } \\
\text { in the warm season (April-October) }\end{array}$ & 10 & 26 & 24 & 22 & 17 \\
\hline
\end{tabular}

- the basin's average daily rainfall depth from the 19612000 period,

- a series of daily flows in the Banska Bystrica cross section from the 1961-2000 period,

- the basin's average mean daily air temperature from the 1961-2000 period,

- the basin's average long-term mean monthly potential evapotranspiration from the 1961-2000 period,

- a set of starting dates of rainfall-induced floods exceeding the bankfull discharge,

- fragments of the temporal distribution of the basin's one-to-five day average rainfalls corresponding with the selected floods.

\section{Description of the rainfall-runoff model}

The Hron rainfall-runoff model, which was developed at the Slovak University of Technology in Bratislava (Kubeš, 2002), was used in this study. This conceptual semidistributed model is based on the principles of the HBV model (Bergström and Forsman, 1973) and contains three basic storage components with 15 calibrated parameters. Surface and subsurface processes can be modelled separately for elevation zones, and the model parameters can also be set up separately for the sub-basins. The scheme of the model is shown in Fig. 6.

The snow sub-model uses the degree-day method for snow accumulation and snowmelt calculations. The sub-model for soil moisture simulation contains four parameters and calculates the soil water storage, groundwater storage and actual evapotranspiration from the soil profile depending on the relation between the water content in the soil profile $S M(\mathrm{~mm})$ and the field capacity value $P K(\mathrm{~mm})$. The actual evaporation from the soil is calculated using a linear relationship (Eqn. 4) until the ratio $S M / P K$ is less than or equal to the limit of the potential evapotranspiration $L P E$. If $S M / P K$ is above $L P E$, the actual evapotranspiration $E_{a c t}$ equals the potential evapotranspiration $E_{p o t}$.

$$
E_{a c t}=E_{p o t}\left(\frac{S M}{P K . L P E}\right)[\mathrm{mm}]
$$

The groundwater recharge is calculated as

$$
\text { recharge }=\left(\frac{S M}{P K}\right)^{R K} \cdot Z(t)[\mathrm{mm}]
$$

where $R K$ is the recharge coefficient and $Z(t)$ is the precipitation and meltwater $[\mathrm{mm}]$.

The soil moisture in time $t$ is calculated as

$$
S M(t)=S M(t-1)+Z(t)-r e c h \arg e[\mathrm{~mm}] .
$$

The runoff sub-model with six parameters consists of one non-linear and one linear reservoir and simulates both quick and slow runoff components (surface and subsurface runoff and base flow). The recharge is added to the upper reservoir with the actual capacity $Z H Z$ (mm). If the $Z H Z$ is above the maximum threshold capacity for subsurface runoff generation $L H Z(\mathrm{~mm})$, surface runoff starts. The parameter $P E R(\mathrm{~mm} /$ day) defines the maximum percolation rate from the upper zone to the lower reservoir with the capacity $Z D Z$ $(\mathrm{mm})$. The basin runoff is calculated as the sum of all the partial runoffs, and it is routed by a discrete cascade of linear reservoirs with a discharge-dependent time parameter (multilinear cascade model).

The precipitation and/or snowmelt water volume is divided between the storage in the soil profile and the upper reservoir according to Eqns. (5) and (6). However, the amount of water in the soil profile $(S M)$ is limited by the field capacity $(P K)$; if $S M$ exceeds the field capacity, the $S M$ is set equal to $P K$, and the remaining volume of water $(P K-S M)$ is added to the upper reservoir's storage together with the groundwater recharge in the same time step (see Fig. 6). Under such circumstances, the upper reservoir can be filled more quickly, which results in higher rates of subsurface and surface runoff. The percolation rate from the upper reservoir to the lower reservoir remains the same in each time step.

Since the rainfall intensity is not compared with the infiltration rate index in the model in the daily time step, this type of runoff generation can be regarded as saturation excess overland flow. Of course, special care has to be exercised when analysing (or extrapolating) the model results in this region of model behaviour, since saturation 


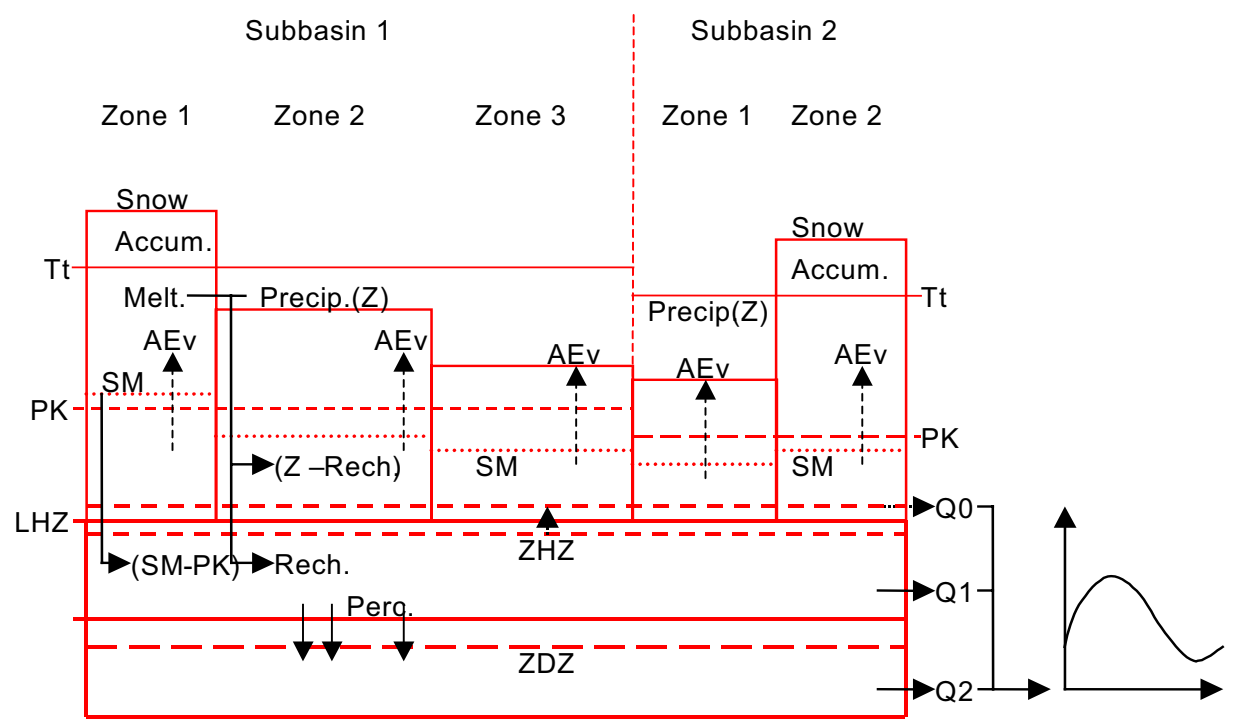

Fig. 6. General scheme of the Hron rainfall-runoff model: Z-precipitation and/or snowmelt water (mm), Tt - the snowmelt threshold temperature $\left({ }^{\circ} \mathrm{C}\right), A E v$ - actual evapotranspiration $(\mathrm{mm}), P K$ - field capacity (mm), SM-soil moisture (mm), LHZ - upper reservoir limit $(\mathrm{mm}), Z H Z$ - storage in upper reservoir $(\mathrm{mm}), Z D Z$ - storage in lower reservoir $(\mathrm{mm})$, Rech. - groundwater recharge (mm), Perc. - percolation rate ( $\mathrm{mm} /$ day), Q0 - surface runoff (if ZHZ exceeds LHZ) (mm), Q1 - subsurface runoff (mm), Q2 - base runoff $(\mathrm{mm})$.

does not build up gradually (as in a contributing area concept) as in nature, nor may the model's behaviour in this highly non-linear region be properly calibrated, since high basin saturation cases may be rare in the calibration dataset. This was taken into account here by using only empirical values of the soil moisture and by restricting the range of extrapolation in the generation process.

Input data needed for runoff simulation with a daily time step are:

- catchment's average mean daily precipitation values,

- catchment's average mean daily air temperature values,

- long-term mean monthly potential evapotranspiration and

- long-term mean monthly air temperature values.

It is also possible to use daily potential evaporation values if they are available. To calibrate the parameters measured, the mean daily discharge values in the closing profile of the selected basin are needed. A more detailed description of the model is given in Kubeš (2002).

\section{Simulations of synthetic floods resulting from $\mathrm{N}$-year 1 to 5 days' rainfall}

First, the rainfall-runoff model was calibrated on the Hron River basin against the discharge data from the 1961-1980 period using a genetic evolution algorithm and verified against the remaining data. More emphasis was paid to the correct reproduction of rainfall floods than snowmelt runoff. The following four criteria can alternatively be used or combined during calibration: the Nash-Sutcliffe criterion for optimalisation $\left(R^{2}\right)$ (Eqn. 7), the mean daily error (Bias) (Eqn. 8), the mean absolute error (Abserr) (Eqn. 9) or the first lag autocorrelation criterion (RCOEF) (Eqn. 10).

$$
\begin{aligned}
& R^{2}=\frac{\sum_{i=1}^{N}\left(Q_{O b s_{i}}-\bar{Q}_{O b s}\right)^{2}-\sum_{i=1}^{N}\left(Q_{O b s_{i}}-Q_{\text {Comp }_{i}}\right)^{2}}{\sum_{i=1}^{N}\left(Q_{O b s_{i}}-\bar{Q}_{O b s}\right)^{2}} \\
& \text { Bias }=\left(\bar{Q}_{\text {Copm }}-\bar{Q}_{O s b}\right) / \bar{Q}_{O b s}
\end{aligned}
$$

$$
\begin{aligned}
& \text { ABSERR }=\frac{1}{N} \sum_{i=1}^{N}\left|Q_{O b s_{i}}-Q_{\text {Obs }}\right| \\
& R C O E F=\frac{\frac{1}{N} \sum_{i=1}^{N}\left(Q_{O b s_{i}}-Q_{\text {comp }}\right)\left(Q_{O b s+1}-Q_{\text {comp }+1}\right)}{\sigma_{o b s} \sigma_{c o m p}}
\end{aligned}
$$

where $N$ is the number of measurements, $Q_{O b s}$ are the observed and $Q_{\text {Comp }}$ the simulated flows, and $\bar{Q}_{O b s}$ and $\bar{Q}_{\text {Comp }}$ are their respective mean values.

An acceptable agreement between the simulated and observed mean daily discharges from the calibration period was achieved, and the fitness of the model for runoff 
simulation in the pilot basin was confirmed by validation. Expressed in terms of the Nash-Sutcliffe criterion, the overall value of 0.86 was considered as sufficient agreement between the measured and simulated discharges in the calibration period and, in the validation period, the value 0.83 was achieved. A comparison of the simulated and measured mean daily discharges for part of the validation period is illustrated in Fig. 7.

The values of the calibrated maximum field capacity play a decisive role in flood runoff simulation. It is recognised that the estimation of the maximum field capacity as a realistic physically-based parameter by automatic calibration in a conceptual model can be meaningless. In the calibration process there is always the possibility of finding a set of maximum field capacities which are outside reasonable values (and the limits given above). For example, by setting the maximum field capacity as a constant value of $80 \mathrm{~mm}$ and $217 \mathrm{~mm}$ in the calibration process, the values of the Nash-Sutcliffe coefficients of 0.76 and 0.78 were reached. Equifinality and other related issues were not treated in this study.

The following procedure for a meaningful estimate was adopted: the calibrated value of the field capacity reached $127.7 \mathrm{~mm}$. To check the credibility of this value, the weighted average values from the catchment's soil field capacities were calculated from a digital soil map, the landuse map and a soil parameter database in a GIS for comparison. Such a weighted average is always parameterised by an estimate of the mean root zone depth of the respective land-use categories. These values often have to be calibrated, even for distributed modelling or are usually taken from the literature for the reference crops of the land-use categories. No measured values are available for the Hron catchment. Therefore, two limiting values of field capacity were estimated for minimum and maximum mean root depths for the respective land-use categories retrieved from the literature and experience. The calibrated maximum field capacity was in the range of these limits, which varied from $100 \mathrm{~mm}$ (for the estimated minimum mean root depth of $0.6 \mathrm{~m}$ in the whole catchment) to 167 $\mathrm{mm}$ (for the estimated maximum mean root depth of $1.00 \mathrm{~m}$ ). The calibrated values were therefore considered as physically meaningful and used in the subsequent flood generator.

Further, a dataset for a study of the relationship between extreme rainfall and the pre-flood soil moisture conditions of the basin was created. From the rainfall-runoff model simulation for the 99 selected floods (higher than bankfull discharge and caused by rainfall), the modelled soil moisture $S M$ values of the day before each selected flood started were taken as characteristics of the water content in the soil of the basin. Other relevant state variables, such as the state of the groundwater reservoir and the distribution of volumes in the upper reservoir, were buffered in the fragments of the model states as well as in the flood generator. [Fig.8]

The soil moisture value varied in the range of $48-122 \mathrm{~mm}$ for all the selected events, which was less than the calibrated maximum field capacity of $127.7 \mathrm{~mm}$. The values are slightly negatively skewed with a mean value of $88.33 \mathrm{~mm}$. In the simulated floods selected, the saturation excess mechanism in the model was triggered during a number of historical events and that type of runoff generation was included in the model parameterisation.

Next, an analysis of the relationship between the modelled pre-flood soil moisture and causative rainfall depths for all the selected floods and rainfall durations was performed. The results of the analysis are shown in Figs. 9-14. The coefficients of the determination were $0.048,0.21,0.20$, $0.16,0.016$ and 0.028 respectively.

It was concluded that the hypothesis of independence can be accepted for the whole dataset. When analysing these relationships in detail, a slight decreasing tendency can be observed for precipitation durations of 1 to 3 days. Nevertheless the hypothesis of the independence of both characteristics was kept. The decreasing tendency is

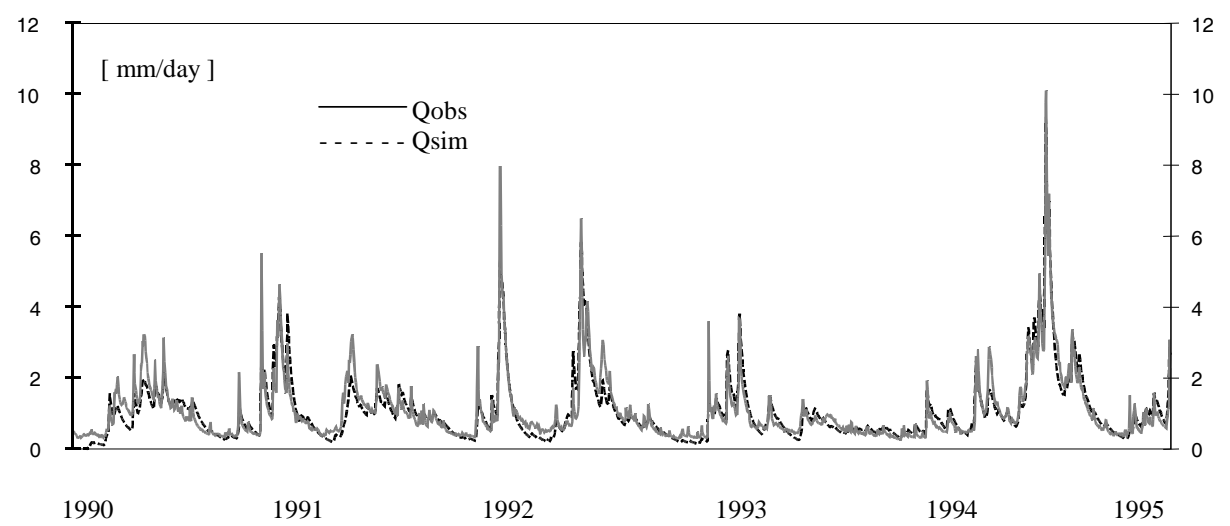

Fig. 7. Comparison of measured and simulated mean daily discharges (mm day $\left.{ }^{-1}\right)$ for part of the validation period. 
Table 2. Summary statistics of the modelled soil moisture $S M$ of the day before each selected flood started.

\begin{tabular}{lrc}
\hline Mean & 88.33 & $\mathrm{~mm}$ \\
Median & 90.84 & $\mathrm{~mm}$ \\
Mode & 109.9 & $\mathrm{~mm}$ \\
Standard Deviation & 18.90 & $\mathrm{~mm}$ \\
Skewness & -0.40 & \\
Range & 73.56 & $\mathrm{~mm}$ \\
Minimum & 48.1 & $\mathrm{~mm}$ \\
Maximum & 121.66 & $\mathrm{~mm}$ \\
\hline
\end{tabular}

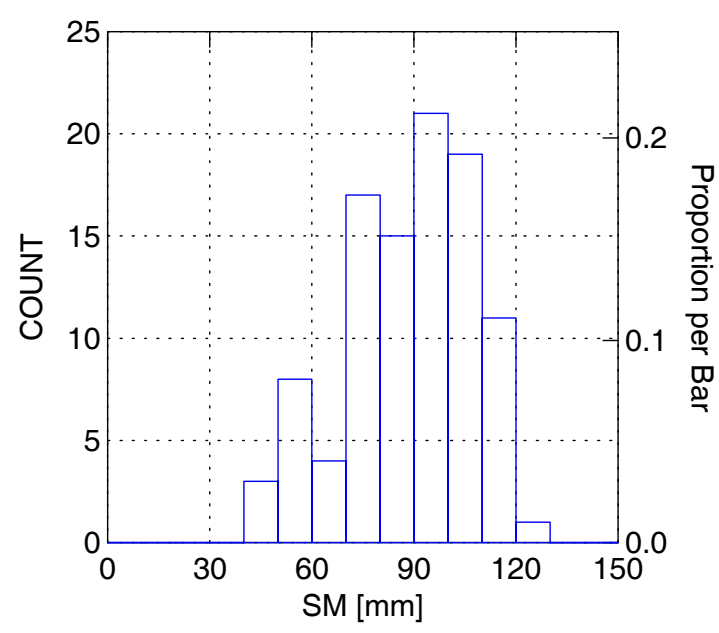

Fig. 8. Histogram of the modelled soil moisture (SM) for the selected floods

attributed partially to the fact that, as a result of the choice of the flood thresholds, smaller floods with presumably low initial soil moisture values are missing in the dataset. The higher values of $R$ for the 1,2 and 3 day rainfall floods are also partially attributed to the sampling, since the results from other basins reported in the literature also support the hypothesis of independence. Unfortunately, the number of floods caused by a 1-day rainfall was very low, indicating that rainfalls of this duration do not play a significant role in a flood regime. The relationship between pre-flood soil moisture and the temporal pattern of a flood causing precipitation was not studied, but was a priori assumed to be independent.

In the next step, input values for the rainfall generator were estimated. From the series of annual maximum 1 to 5 day precipitation depths selected from the warm season events, 5, 20, 50 and 100-year values were estimated by statistical analysis. The availability of just 40 years of data, which provided 40 of the basin's annual maximum rainfalls for each rainfall duration, could introduce substantial

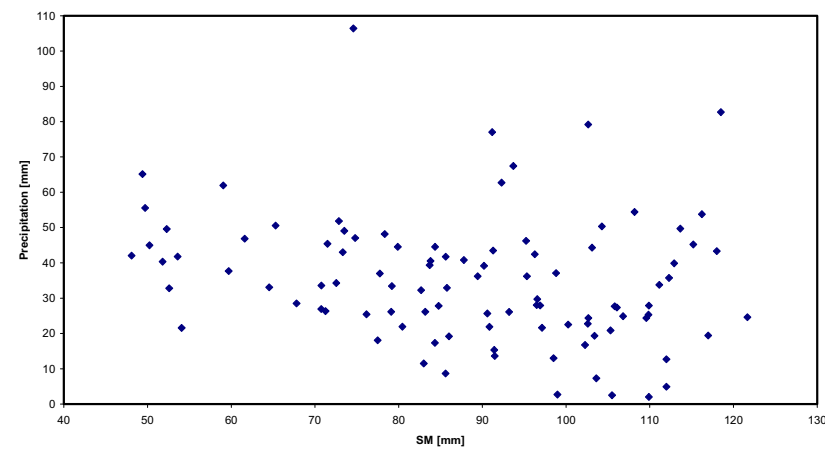

Fig. 9. Relationship between the soil moisture values and causal precipitation depths for the all selected floods.

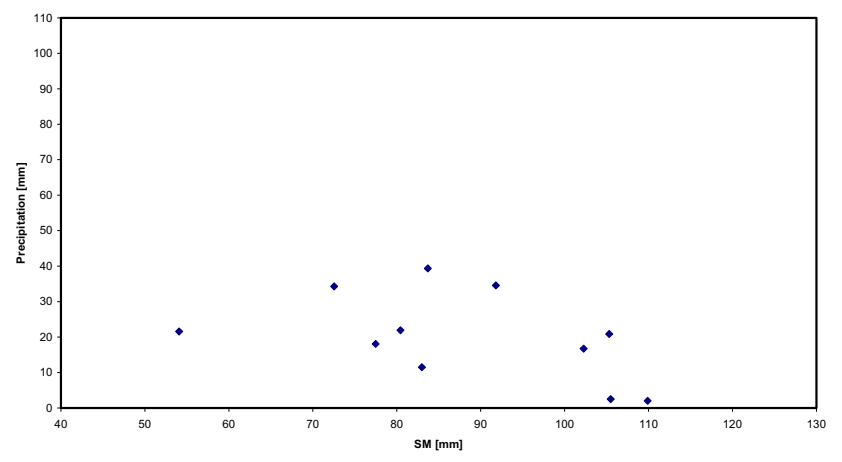

Fig. 10. Relationship between the soil moisture values and causal precipitation depths for floods caused by a l-day rainfall.

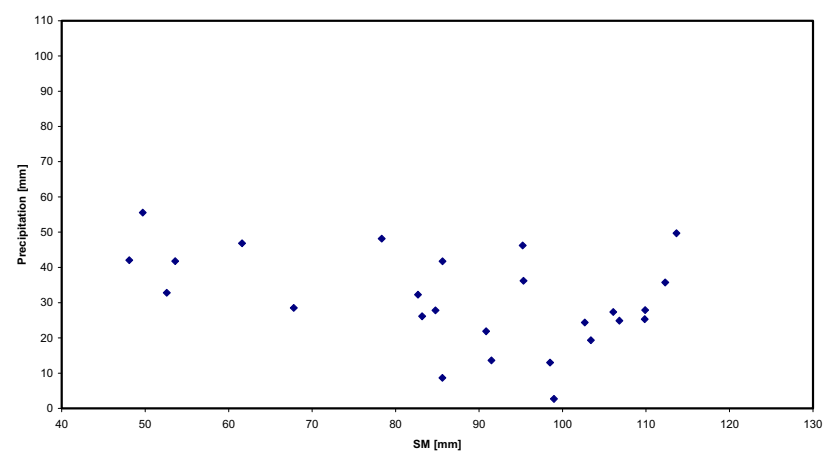

Fig. 11. Relationship between the soil moisture values and causal precipitation depths for floods caused by a 2-days rainfall.

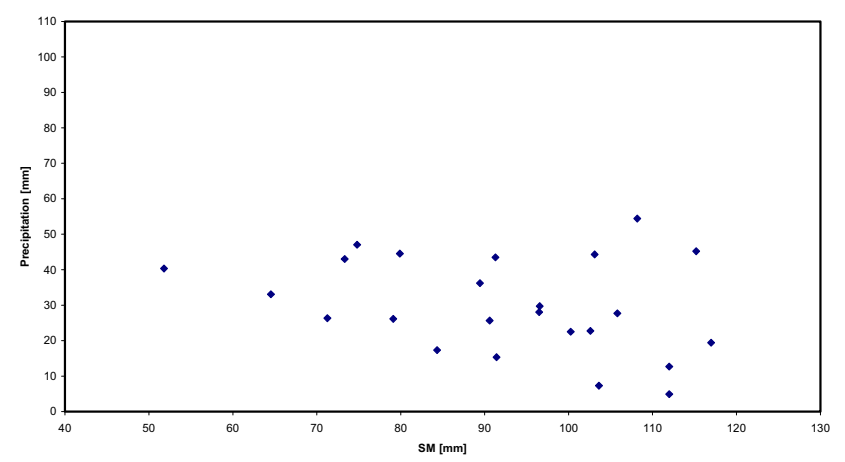

Fig. 12 Relationship between the soil moisture values and causal precipitation depths for floods caused by a 3-days rainfall. 


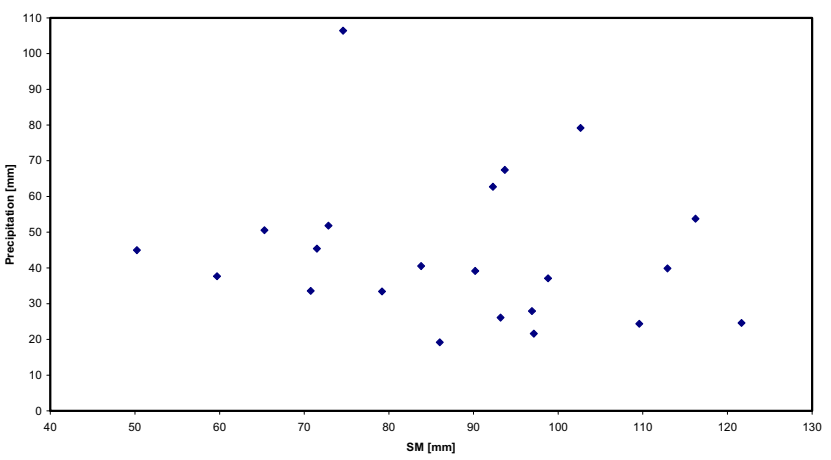

Fig. 13. Relationship between the soil moisture values and causal precipitation depths for floods caused by a 4-days rainfall.

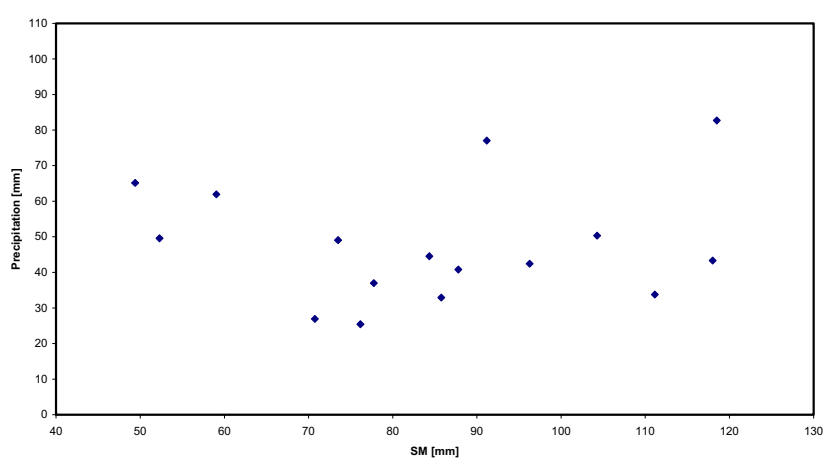

Fig. 14. Relationship between the soil moisture values and causal precipitation depths for floods caused by a 5-days rainfall.

uncertainty in the results for such an analysis when employed as usual in rainfall frequency analysis. This has to be recognised but, for the given purpose, it is not a critical problem. Given the sparse dataset, return periods and associated design values used for flood protection activities in the basin have the same degree of uncertainty as in real life. These values are also accepted as consensual thresholds by subjects involved in flood protection; that gives them a particular practical and generally accepted sense.

Such practically accepted ('valid') values will be used here as measures of the danger of forthcoming events for flood warnings, so there is no need to treat the uncertainty problem in a special way. Moreover, it was decided in the proposed method not to use events with a higher return period than 100 years. According to the present views and accepted standards of the potential users in the broader region of central Europe, it is widely acceptable to estimate it from 40 years of data (DVWK, 1999).

The same applies to the choice of the frequency distribution and parameter estimation method. The number of statistically acceptable distribution functions was rather high for all the durations of rainfall but, as illustrated by a comparison of the design precipitation values estimated with

statistically acceptable methods selected according to the German Technical Standards (DVWK) in Table 3, these may not exhibit significant differences for the given practical purpose. Therefore, the following accepted engineering principles in the region, the generally accepted GEV distribution and the widely used method of L-moments for fitting the distribution were adopted.

As a consequence of the assumption of the independence of the initial basin state and the magnitude and temporal distribution of flood-inducing rainfall events, the following simple event- based flood generation scheme was adopted:

- A set of fragments of the modelled basin's pre-flood initial conditions was created by selecting and storing

Table 3. Illustrative comparison of the basin's average design precipitation values estimated by statistically accepted different frequency distributions and parameter estimation methods according to the German Technical Standard (DVWK, 1999). (Distribution functions: the Gumbel (EV1), the General Extreme Value (GEV), Pearson III (P3), Rossi (ME), and Weibull (WB). Parameter estimation methods: MOM - method of moments, MLM - maximum likelihood, PWM - probability weighted moments).

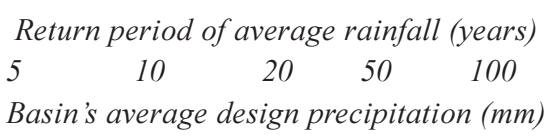

1 day

P3(PWM)

WB3(PWM)

GEV (PWM)

37.4

37.6

37.0

42.9

43.1

42.5

2 days

P3(MM)

WB(MLM)

GEV (PWM)

49.4

49.1

49.3

53.9

54.3

54.1

3 days

EV1(PWM)

ME(MLM)

GEV (PWM)

4 days

LN3 (PWM)

P3 (PWM)

GEV(PWM)

5 days

EV1(PWM)

LN3 (PWM)

GEV(PWM)
58.9

58.0

58.5

66.4

66.1

66.1

68.0

68.1

78.1

77.8

74.5

74.9

85.0

84.9

\begin{tabular}{l}
74.9 \\
\hline
\end{tabular}
48.1

$48.2 \quad 58.8$

$48.0 \quad 55.5$

57.8

58.4

58.3

62.4

63.2

63.3

65.6

66.5

66.7

72.8

83.2

90.1

$74.2 \quad 85.6$

94.9

$\begin{array}{lll}74.3 & 84.8 & 94.9\end{array}$

$88.0 \quad 101.0 \quad 111.0$

$88.1 \quad 100.0 \quad 109.0$

$87.9 \quad 102.0 \quad 113.0$ 
all the basin's state variables from the rainfall-runoff model at the beginning of the selected set of past floods.

- Fragments consisting of the temporal distribution of flood-causing rainfall scaled by the rainfall depth were formed.

- Synthetic rainfall scenarios were created as a product of the 5, 20, 50 and 100-year rainfall depths and the fragments of the temporal distribution of rainfall from the past.

- Synthetic flood waves were generated from random combinations of the rainfall scenarios and fragments of historical pre-flood soil moisture conditions. To avoid complications from the probabilistic modelling of the proportion of rainfall with different durations and the frequency distribution of the soil moisture, the distribution of both quantities was considered equal to the empirical ones. Moreover, the duration of rainfalls was kept equal to the historical ones for a given basin state.

As an example of such a series of simulated floods for a historical flood, the year 1984 is shown in Fig. 15. Such a scenario-based method is believed to be sufficient for an analysis of the return periods of hypothetical simulated floods which could have occurred in the basin in the course of a set of historical flood situations, if the real flood-causing precipitation had been replaced by a synthetic event with the same duration and temporal distribution as the observed one, but with rainfall depths with a given probability of exceedance. However, in no case could such a scheme be sufficient for flood frequency analysis. Dangerous floods can be caused by peculiar combinations of soil moisture and amount and temporal distribution of rainfall. The procedure used here reduces the possible combinations and that would alter evaluation of the return period of the flood peaks generated for flood frequency analysis.

Subsequently, the return period of the synthetic flood peaks was determined. The relationship of the return periods of the causative precipitation $N P$, the resulting synthetic flood wave $N Q$ and the soil moisture $S M$ occurring before the event (as computed by the model) were analysed.

The overall relationships between the return periods of the floods determined for the synthetic flood-inducing precipitation with a duration of 1 to 5 days, the return period $N P$ of 5, 20, 50 and 100 years and soil moisture $S M$, without distinguishing the duration of the rainfall, is shown in Fig. 16a. The relationship is highly non-linear; around the value $S M$ equal to $110 \mathrm{~mm}$, the basin starts to develop a strong reaction to the flood-causing rainfall. No theoretical model was thought through for such a reaction here. To illustrate this feature better, the simulated return periods were fitted by high-order polynomial relationships in Fig. 16a. However, the use of such relationships for the estimation of $S M$ values for which $N P$ equals $N Q$ is not foreseen since, in the range of these $S M$ values, extrapolated data have to be used for soil moisture values near basin saturation.

For comparison, relationships between the return periods of the observed floods NQobs, the observed flood-inducing precipitation with a duration of 1 to 5 days, the return period NPobs and the modelled soil moisture SM is shown in Fig. 16b. Actual observations do not allow conclusions about rare events, because the return period of the observed

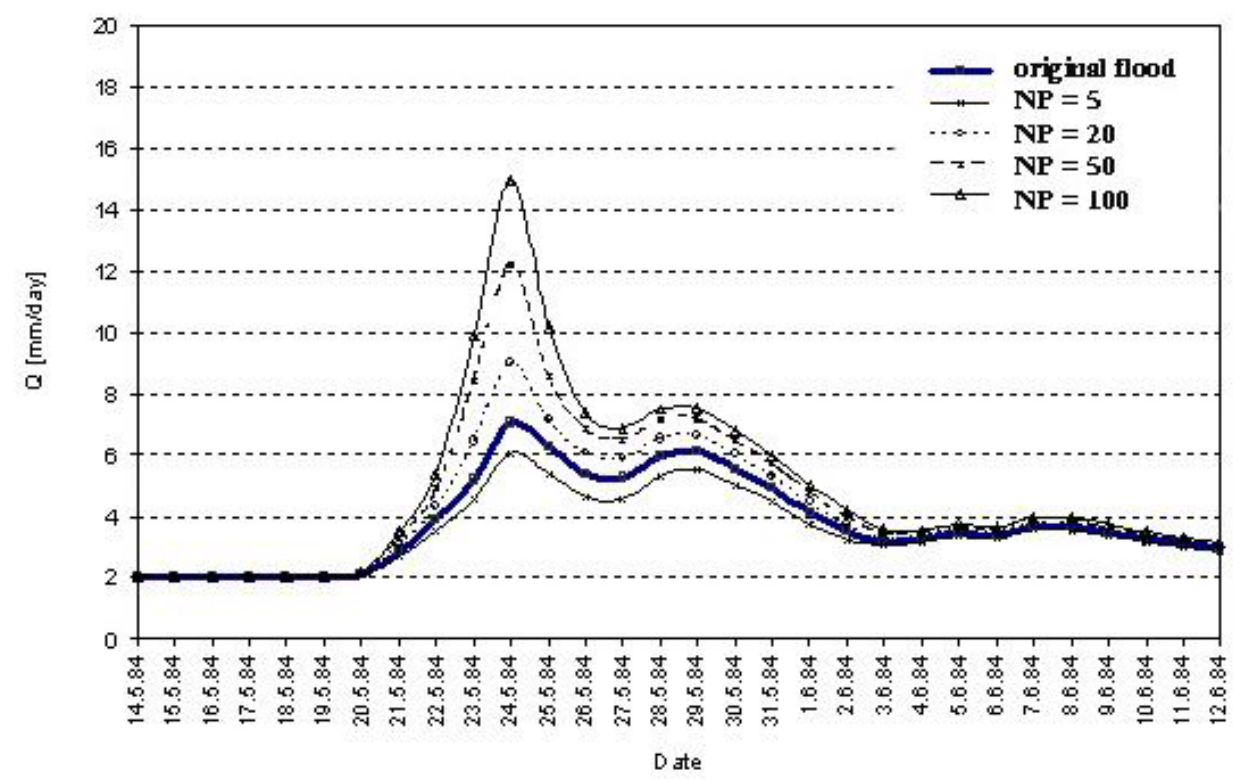

Fig. 15. Simulations of floods caused by synthetic precipitation with durations of 5 days and return period of 5 to 100 years in 1984 . 
precipitation exceeded 10 years (NPobs $=50$ years) in only one case and that of the floods approximately 5 years. The overall tendency of the relationships is in agreement with the simulated data.

Instead, and also to get a better insight into the reaction of the basin to rainfall of different durations, the relationships between these quantities were studied separately for each rainfall duration and the return period of that rainfall. Figure 16 shows an example of such a relationship for the rainfall duration of 2 days and return period of 50 years.

Again, without a theoretical analysis, it is difficult to derive plausible $S M$ values for which the return period of floods starts to exceed that of the rainfall. To illustrate the problem, linear and non-linear models are fitted to the data in Fig. 17. It was not possible to find a unique 'best type' non-linear relationship for all the data. However, in all cases the critical $S M$ values were higher for the non-linear relationship than for the linear case. It was decided to take the estimate from the linear model as a conservative estimate of the critical state of the basin. This choice can be supported by the argument that due to the restrictive character of the simplifications adopted in the method, important data are missing in this critical region, and non-linear extrapolation would therefore not be sensible.

The critical soil moisture values read from the fitted linear relationships for the ratio $N P / N Q=1$ are listed in Table 4 for flood-inducing rainfall with a duration of 1,2,3,4 and 5 days separately and compared with values of $S M$ obtained by fitting the linear relationship to the data from Fig. 16a. For this given catchment, there seems to be a slowly decreasing value for the critical soil moisture with the increasing duration of the precipitation. This seems to be logical for the calibrated field capacity of $127.7 \mathrm{~mm}$ which has to be reached to trigger more extreme runoff generation in the basin. When these values are exceeded, it is very likely that the return period of floods will be higher than that of the basin's average flood-inducing precipitation. (Note that the values for a 1-day rainfall were derived from a relatively small number of cases).

This feature may be basin-specific, but it can be used in

(a)

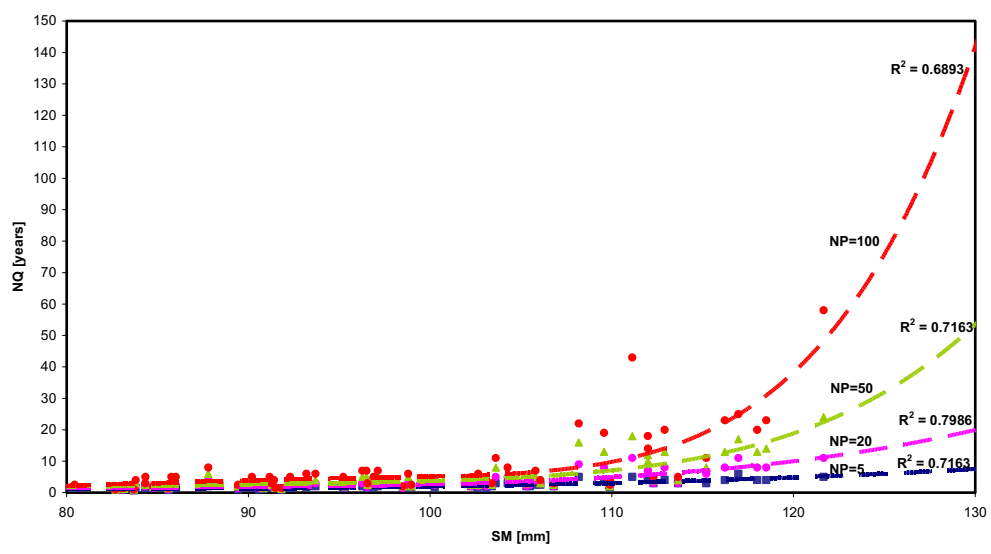

(b)

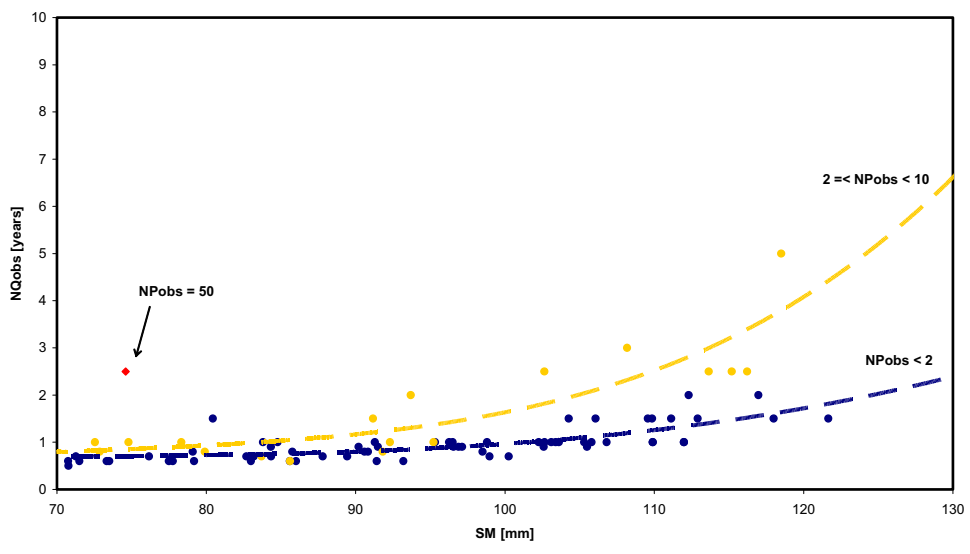

Fig. 16. (a) Relationships between the return periods of generated floods NQ and soil moisture SM for all rainfall durations and the corresponding coefficients of determination. (b) Relationships between the return periods of the observed floods NQobs and the modelled soil moisture SM for all rainfall durations. 


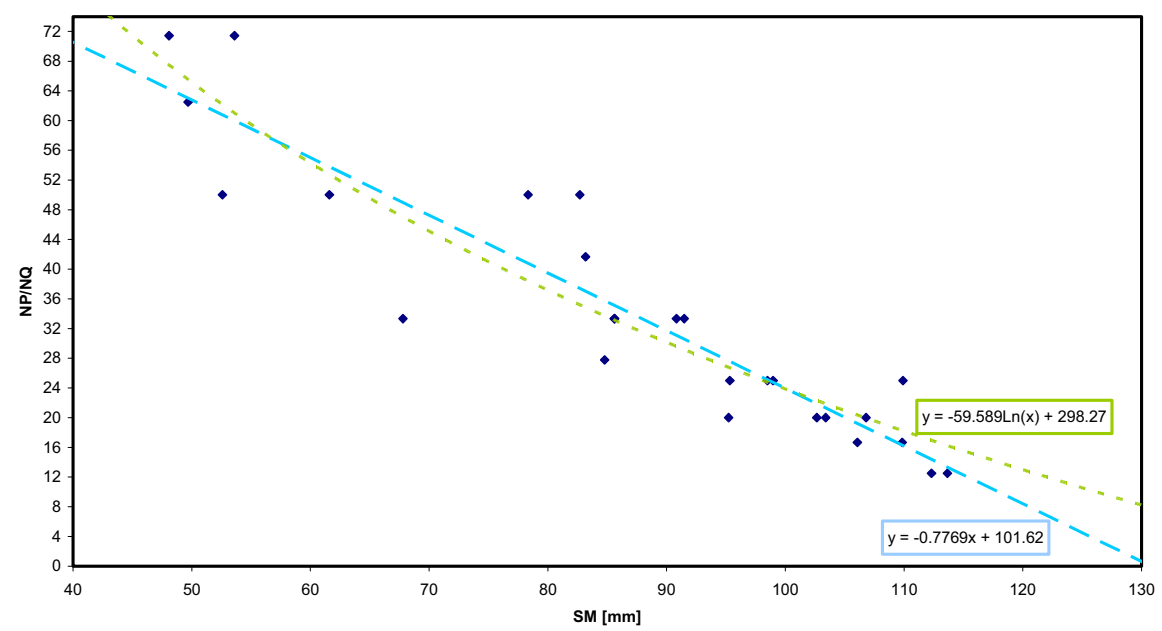

Fig. 17. Relationship between the ratio of the return periods of synthetic precipitation NP and generated floods NQ, and soil moisture SM for the rainfall duration of 2 days and NP of 50 years.

the Hron basin's flood warning system for the real-time estimation of the degree of extremity of flood events that might occur in the course of forthcoming dangerous meteorological situations. Figure 17 indicates how this feature can be used as a simple decision support tool. This figure relates the return period of the precipitation to the expected return period of a flood for different soil moisture values.

To arrive at such relationships by the flood generation method presented here, it was decided not to use any of the fitted relationships shown in Figs. 16a or 17, which would introduce artefacts into the graphs due to extrapolation errors in the critical regions of SM values conditioned by the choice of the type of non-linearity. Instead, it is suggested to use the empirical information contained in the simulated data and not to extrapolate. The average values of the ratio of $N P / N Q$ were therefore estimated for a moving window of $S M$ values, and these values were fitted into the relationships proposed for decision support. As can be seen from Fig. 18, a region of critical basin reactions can be identified for the given $S M$ values and estimates of the return period of the forthcoming rain.

To verify the relationships, the same type of information was retrieved from the linear models in Fig. 19; according to these, the basin's reaction is more extreme for the same pairs of $N P$ and $S M$ values, especially for higher $S M$ values. That is in agreement with Fig. 17, where for higher $S M$ values the ratio $N P / N Q$ is higher for the fitted non-linear relationship in comparison with the linear model.

Due to the restrictive character of the stochastic generation scheme adopted here, resulting from the information in the critical range being limited, extrapolation beyond the range of the simulations was omitted. Despite this limitation, it is believed that these estimates can be used as useful additional
Table 4. Critical values of $S M$ (when $N P / N Q=1$ ) for different return periods of synthetic precipitation for all the rainfall durations for the fitted linear relationships.

\begin{tabular}{lcccc}
\hline $\begin{array}{l}\text { Rainfall duration } \\
\text { (days) }\end{array}$ & 5 & \multicolumn{4}{c}{ NP (years) } \\
& \multicolumn{5}{c}{ Critical soil moisture value } \\
& $m m$ & $m m$ & $m m$ & $m m$ \\
& & & & \\
& 130 & 140 & 130 & 129 \\
1 & 120 & 129 & 130 & 126 \\
2 & 115 & 116 & 116 & 116 \\
3 & 116 & 118 & 117 & 116 \\
4 & 112 & 112 & 112 & 112 \\
5 & 117 & 121 & 121 & 120 \\
$1-5$ & & &
\end{tabular}

information in flood warnings and may help decision-makers to take preliminary precautionary measures well in advance. They indicate critical behaviour clearly and simply and can thereby increase flood awareness.

\section{Conclusions}

Simulations of the joint occurrence of extreme precipitation and various antecedent saturations of a basin have confirmed and quantified the expected strong effect of antecedent basin saturation on a flood's severity. In all the simulated events, flood severity increased with increases in the antecedent basin saturation but in no case was the return period of a flood higher than the return period of the causal precipitation. This could be attributed to the simplifications in the generation scheme or it could also be a property of the particular basin. This problem was not resolved in this 
study but it has been taken into account in the extrapolation of the results for the decision support tool.

Despite this, the proposed scenario-based method is believed be sufficient for an analysis of the return periods of hypothetical simulated floods which could have occurred in the basin in the course of a set of historical observed flood situations, if the real flood-causing precipitation were substituted by a synthetic event with the same duration and temporal distribution as that of the observed but with rainfall depths with a given probability of exceedance. However, in no case could such a scheme be sufficient for flood frequency analysis. Dangerous floods can be caused by peculiar combinations of soil moisture and amount and temporal distribution of rainfall. The procedure used here reduces the possible combinations and that would alter evaluation of the return period of the flood peaks generated for flood frequency analysis.
The non-linearity of the relationship between the ratio of the return periods of precipitation and floods and the soil moisture increased with an increase in the causative precipitation's return period. With increasing duration of rainfall there seems to be a slowly decreasing value for critical soil moisture for which the return period of the flood is equal to that of the rainfall for this particular catchment. But it was also shown in the Hron River basin that this range is rather small and practically independent of the return period and the duration of the causal precipitation; a critical value for soil moisture can be indicated when the return period of a flood starts to be higher than the return period of the causal precipitation. This fact and the derived relationships relating the return periods of floods to the soil moisture can be exploited in a flood warning system in the basin.

The results of the study can be used in estimating flood

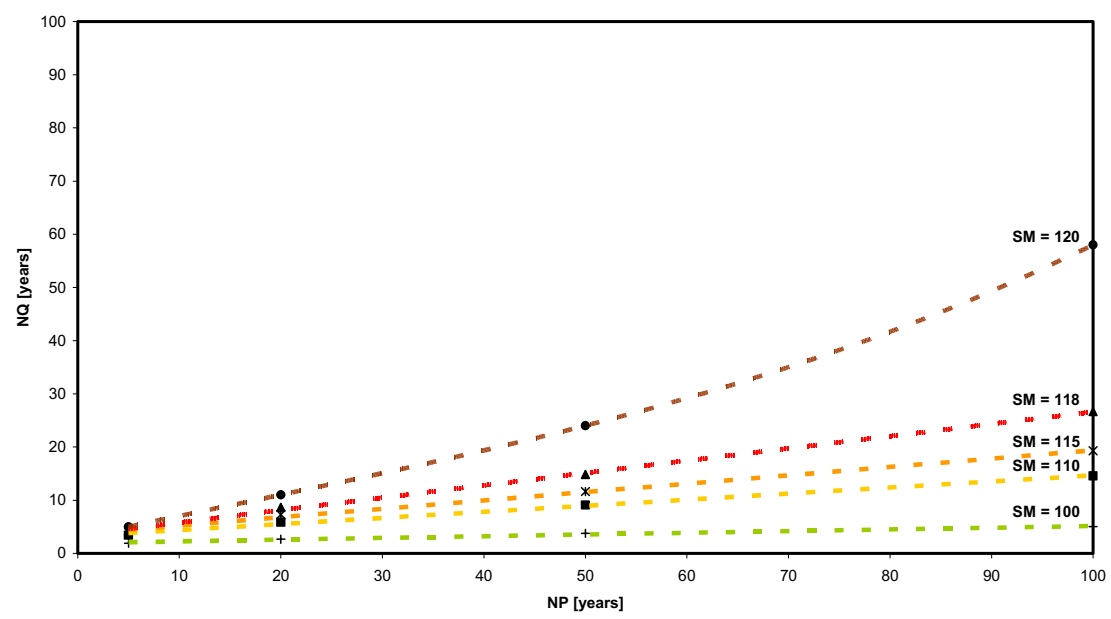

Fig. 18. Relationships of the return period of precipitation to the expected return period of a flood for different soil moisture values estimated directly from the simulated data.

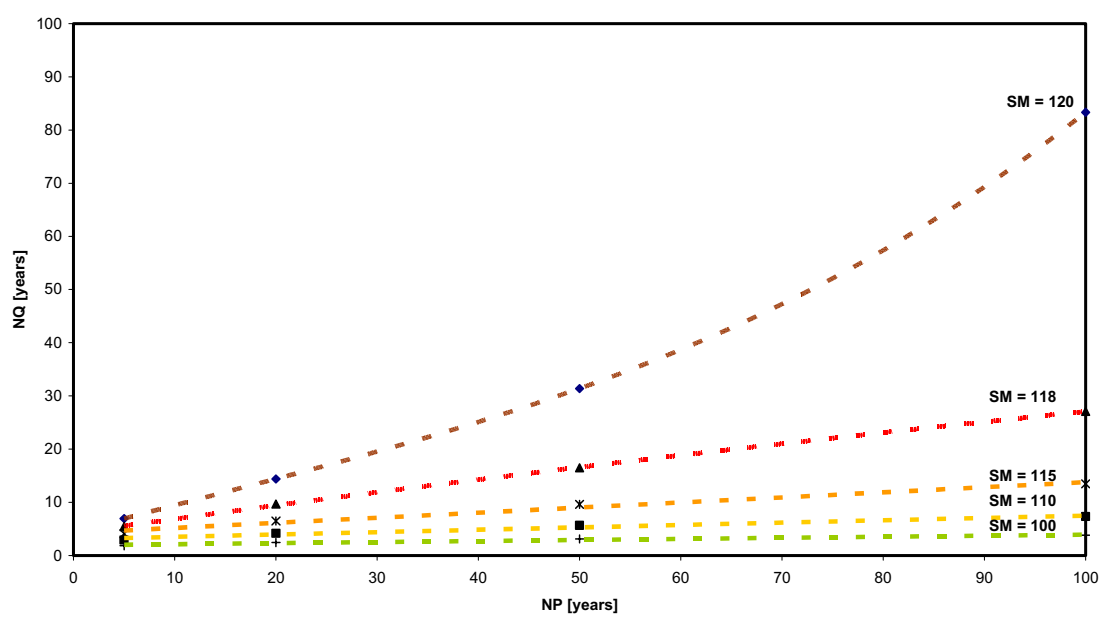

Fig. 19. Relationships of the return period of precipitation to the expected return period of a flood for different soil moisture values derived from linear models. 
risk and flood protection in the Hron River basin. The critical soil moisture values can be determined either by monitoring the antecedent soil moisture in the basin continually or by continual runoff simulation with a hydrological model. The results can also be applied in design flood estimation in the Hron basin, but they should be confirmed for other basins. The method also gives decision-makers insight into how the basin might have behaved in past critical situations if the rainfall had been different so that they could use this information as a decision support aid. It could also be an advantage that at least some of the events may have been experienced personally by the specialists involved in the decision-making, so that the results of the generation scheme could be psychologically more acceptable than floods created by a more sophisticated fully stochastic scheme.

\section{Acknowledgement}

The authors gratefully acknowledge the VEGA grant agency for the support of grants $1 / 1145 / 04$ and 1/2032/05.

\section{References}

Bartels, H., Malitz, G., Asmus, S., Albrecht, F.M., Dietzer, B., Günther, T. and Ertel, H., 1997. Starkniederschlagshöhen für Deutschland (KOSTRA). Selbstverlag des DWD, Offenbach am Main.

Bergström, S. and Forsman, A., 1973. Development of a conceptual deterministic rainfall-runoff model. Nordic Hydrol., 4, 147-170.

Bergström, S., Harlin, J. and Lindström, G., 1992. Spillway design floods in Sweden: I. New guidelines. Hydrolog. Sci. J., 37, 505519

Burn, D.H., 1990: Evaluation of Regional Flood Frequency Analysis With a Region of Influence Approach. Water Resout. Res., 26, 2257-2265.

Calver, A. and Lamb, R., 1996. River flood frequency estimation using continuos runoff modelling. Proc. Inst. Civil Eng. Water, Marit., 136, 225-234.

Cameron, D.S., Beven, K.J., Tawn, J., Blazkova, S, and Naden, P., 1999. Flod frequency estimation by continuous simulation for a gauged unpland catchment (with uncertainty), J. Hydrol., 219, 169-187.

Cameron, D., Beven, K., Tawn, J. and Naden, P., 2000a. Flood frequency estimation by continuous simulation under climate change (with likehood based uncertainty estimation). Hydrol. Earth Syst. Sci., 4., 23-34.

Cameron, D., Beven, K. and Naden, P., 2000b. Flood frequency estimation by continuous simulation under climate change (with uncertainty). Hydrol. Earth Syst. Sci., 4, 393-405.

Cunderlík, J., 1999. Regional estimation of $N$-year maximum floods in selected catchments in Slovakia. PhD Thesis, FCE SUT, Bratislava. 144pp.

DVWK Regeln 101/1999. 1999. Wahl des Bemessungshochwassers. (German Technical Standard - The choice of the design flood. In German.) Verlag Paul Parey, Hamburg.

Faulkner, D.S. and Jones, D.A, 1999. The FORGEX method of rainfall growth estimation III: Examples and confidence intervals. Hydrol. Earth Syst. Sci., 3, 205-212.
FEH, 1999. Flood Estimation Handbook. Part 3. Statistical procedures for flood frequency estimation. IH Wallingford, UK. $325 \mathrm{pp}$.

Frannchini, M., and Pacciani, M., 1991. Comparative analysis of several conceptual rainfall-runoff models. J. Hydrol., 122, 161219.

Franchini, M., Helmlinger, K.R., Foufoula-Georgiou, E. and Todini, E., 1996. Stochastic storm transposition coupled with rainfall-runoff modelling for estimation of exceedance probabilities of design floods. J. Hydrol., 175, 511-532.

Franchini, M., Hashemi, A.M. and O'Connell, P.E., 2000. Climatic and basin factors affecting the flood frequency curve: PART II - A full sensitivity analysis based on the continuous simulation approach combined with a factorial experimental design. Hydrol. Earth Syst. Sci., 4, 483-498.

Foufoula-Georgiou, E., 1989. A probabilistic storm transposition approach for estimating exceedance probabilities of extreme precipitation depth. Water Resour. Res., 25, 799-815.

Geiger, H., Stehli, A. and Castellazzi, U., 1986. Regionalisierung der Starkniederschläge und Ermittlung typischer Niederschlagsganglinien. In: Beitrage zur Geologie der Schweiz - Hydrologie, Nr. 33. 320pp.

Grebner, D., 1995. Klimatologie und Regionalisierung starker Gebietsniederschläge in der nordalpinen Schweiz. Zürcher Geographische Schriften, Nr. 59, Geographisches Institut, Eidgenössische Technische Hochschule, Zürich.

Hashemi, A.M., Franchini, M. and O'Connell, P.E., 2000. Climatic and basin factors affecting the flood frequency curve: PART IA simple sensitivity analysis based on the continuous simulation approach, Hydrol. Earth Syst. Sci., 4, 463-482.

Jensen, H., 1986. Regionalisierung der Verteilungsfunktion des jährlichen Maximums des Tagesniederschlages im Kanton Zürich. Zürcher Geographische Schriften, Nr. 27, Geographisches Institut, Eidgenössische Technische Hochschule, Zürich.

Kluge, CH., 1996: Statistische Analyse von Hochwasserdurchfluessen. Dresdner Berichte, TU Dresden, H. 7.

Kubeš, R., 2002. Applying the rainfall-runoff model in simulation of extreme runoff. The $14^{\text {st }}$ Conference of Young Hydrologists. Works and Studies of SHMI, 66, SHMI, Bratislava, 29-40.

Lindström, G., Johansson, B., Person, M., Gardelin, M. and Bergström, S., 1997. Development and test of the distributed HBV-96 hydrological model. J. Hydrol., 201, 272-228.

Liu, Y.B., Gebremeskel, S., De Smedt, F., Hoffmann, L. and Pfister, L., 2003. A diffusive transport approach for flow routing in GISbased flood modelling. J. Hydrol., 283, 91-106.

Malitz, G, 1999. Starkniederschlag in Deutschland Messergebnisse, statistische Auswertungen, Schätzungen. Klimastatusbericht des DWD, 35-41.

Miklánek, P., Halmová, D. and Pekárová, P., 2000. Extreme Runoff Simulation in the Mala Svinka Basin. Conf. Monitoring and Modelling Catchment Water Quality and Quantity. Laboratory of Hydrology and Water Management, Ghent University, Belgium. 49-52.

Rahman, A., Weinmann, P.E., Hoang, T.M.T. and Laurenson, E.M., 2002. Monte Carlo simulation of flood frequency curves from rainfall. J. Hydrol., 256, 196-210.

Reed, D.W., Faulkner, D.S. and Stewart, E.J., 1999. The FORGEX method of rainfall growth estimation II: Description. Hydrol. Earth Syst. Sci., 3., 197-203.

Schaefer, M.G., 1990. Regional analyses of precipitation annual maximal in Washington State. Water Resour. Res., 26, 119-131.

Smithers, J.C. and Schulze, R.E., 2001. A methodology for the estimation of short duration design storms in South Africa using a regional approach based on L-moments. J. Hydrol., 241, 4252. 
Svanidze, G.G., 1997. Matematiceskoe modelirovanie gidrologiceskych rjadov. Gidrometeoizdat, Leningrad. (In Russian)

Svoboda, A., Pekárová, P. and Miklánek, P., 2000. Flood Hydrology of the Danube River Between Devin and Nagymaros. Publication of the Slovak Committee for Hydrology No.5. SCH, IH SAS, Bratislava. 97pp.

Srikhanthan, R. and Mc Mahon, T.A., 1980. Stochastic generation of monthly flows for ephemenral streams. J. Hydrol., 47, 1940 .
Srikhanthan, R. and McMahon, T.A., 1982. Stochastic generation of monthly streamflow. J. Hydraul. Div. ASCE, 108, 419-441.

Thomson, C.S., 2002. The high intensity rainfall design system, HIRDS. Int.Conf. Flood Estimation, Berne, Switzerland, 273283.

Wilson, L.L. and Foufoula-Georgiou, E., 1990. Regional rainfall frequency analysis via stochastic storm transposition. J. Hydrol. Eng. ASCE, 116, 859-880. 